\title{
Wearable Computing System with Input-Output Devices Based on Eye-Based Human Computer Interaction Allowing Location Based Web Services
}

\author{
Kohei Arai \\ Graduate School of Science and Engineering \\ Saga University \\ Saga City, Japan
}

\begin{abstract}
Wearable computing with Input-Output devices Base on Eye-Based Human Computer Interaction: EBHCI which allows location based web services including navigation, location/attitude/health condition monitoring is proposed. Through implementation of the proposed wearable computing system, all the functionality is confirmed. It is also found that the system does work well. It can be used easily and also is not expensive. Experimental results for EBHCI show excellent performance in terms of key-in accuracy as well as input speed. It is accessible to internet, obviously, and has search engine capability.
\end{abstract}

Keywords-eye based human computer interaction; wearable computing; location based web services

\section{INTRODUCTION}

For many years, wearable computing system has been studied. Not so small number of wearable computing systems has been proposed so far. One of the difficult problems on wearable computing systems is input and output devices in particular input device. There are some proposed input devices for wearable computing systems such as "Project Glass"1 and "Contact Lens". such as projector which allows display a keyboard on hand or arm, and contact lens which has keyboard layout in the lens. On the other hand, Eye-Based Human Computer Interaction: EBHCI is proposed together with camera mouse [1]-[27]. EBHCI can be used as computer input device with human eyes only. Also camera mouse allows the entire mouse operations (click right and left button and drag and drop operations) with human eyes only. Computer input can be done with just by sight. EBHCI requires just web cameras, and display with Bluetooth capability. Furthermore, only thing users have to do is just looking at the desired key which is displayed onto Head mount Display: HMD. Also users can easily manipulate mouse with their eyes by looking at the icons. Therefore, EBHCI based wearable computing system can be created with not so expensive cost. Furthermore, it is easy to use.

In this paper, EBHCI based computer input device is proposed together with wearable computing system utilizing

\footnotetext{
${ }^{1}$ http://arkouji.cocolog-nifty.com/blog/2013/01/googleproject-g.html

${ }^{2}$ lhttp://commonpost.boo.jp/?p=19724

http://japanese.engadget.com/2008/01/17/researchers-put-circuits-on-
} contact-

lenses-freak-out-rabbits/
EBHCI based device. Users may use web services including search engine during making actions. For instance, users may use search engine when they are walking. A variety of applications is available with the proposed wearable computing system. For example, users are navigated with the proposed system. One of key issues here is computer key-in devices, camera mouse, and indoor location estimation. Key-in accuracy of the proposed system, therefore, has to be clarified together with indoor location estimation accuracy.

The following section describes the proposed wearable computing system and examples of the applications of the proposed system. Then key-in accuracy assessment results is followed by through some experiments together with the indoor location estimation accuracy evaluation results. Then conclusion is described together with some discussions.

\section{PROPOSED METHOD}

\section{A. Configuration of the Proposed Wearable Computing System}

Configuration of the proposed wearable computing system is shown in Figure 1.

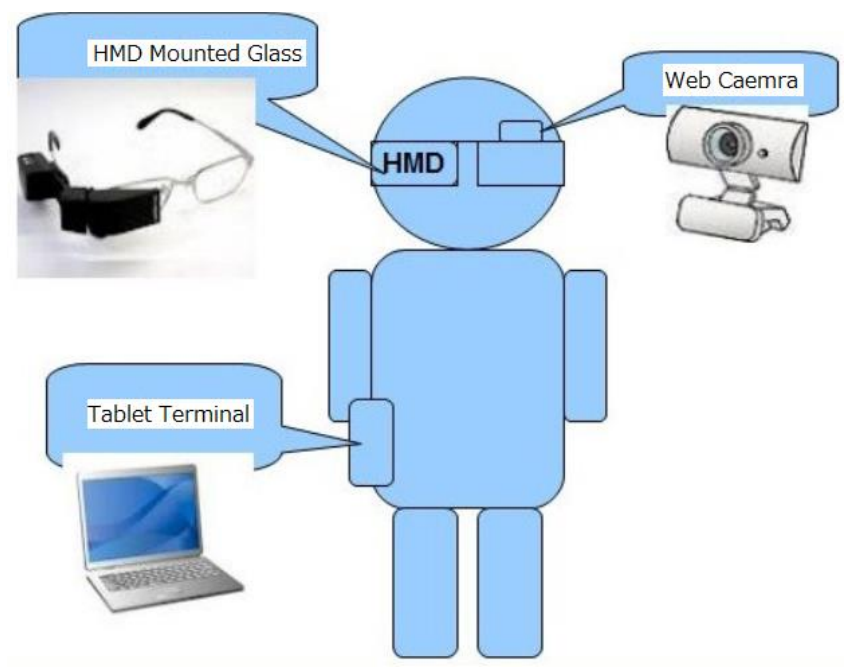

Fig.1. Configuration of the proposed wearable computing system

Users wear the Head Mount Display: HMD mounted glass. The glass also carries backward looking camera. The backward 
looking camera looks users' eye. Users' line of sight can be estimated with the acquired images of the backward looking camera. The HMD and the backward looking camera are connected to tablet terminals through wire and / or Bluetooth communication as shown in Figure 2.

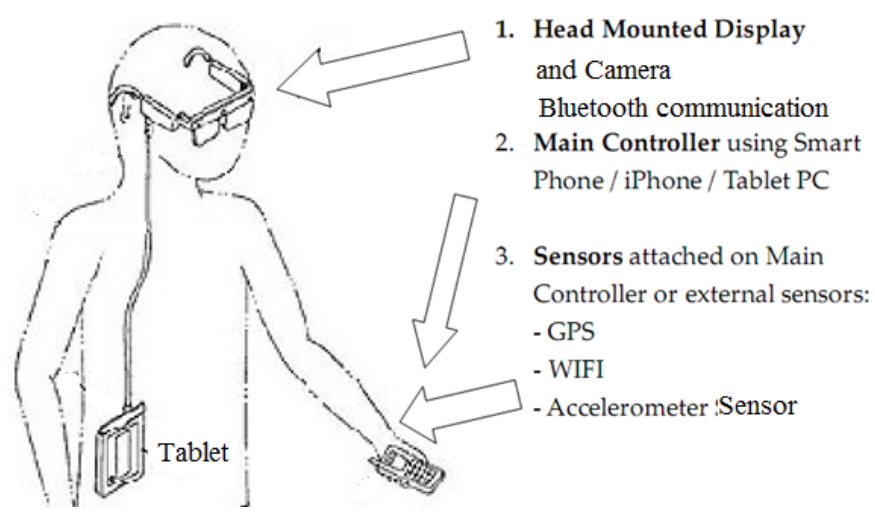

Fig.2. Connections HMD and the backward looking camera to tablet PC and / or mobile phones

The required processes for estimation of the position at which users is looking on the display screen of the HMD through line of sight estimation are done in the Tablet PC. Also gathered data of the user's location and accelerometer data are handled in the mobile terminals or Tablet PC. Therefore, user's location can be known with the GPS receiver data. Even if the user is situated indoor, WiFi capability allows estimation of the user's location by using signal lengths from the nearest three WiFi access points

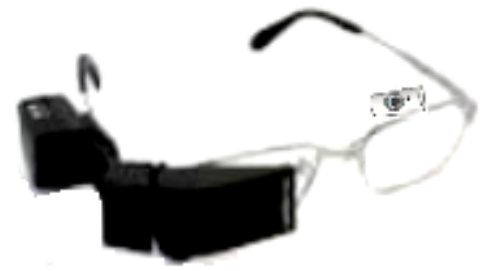

Fig.3. Single HMD and backward looking camera mounted glass

\section{B. Computer Key-in with Eye Based Human-Computer Interaction: $\mathrm{EBHCI}$}

One of the key issues here is computer key-in with EyeBased Human-Computer Interaction EBHCI and Eye-Based mouse as well as location estimation based on the received signal lengths from $\mathrm{WiFi}$ access points.

EBHCI uses moving keyboard which is shown in Figure 4. On the typical key layout, there is five enlarged keys. The key at which user is looking is shown at the center key of the enlarged five keys. The character of the center key, therefore, may change depending on the gaze location where user is looking at. When user looks one of the four surrounding keys, left, right, top and bottom, then characters for the five enlarged keys are changed in accordance with user's gaze location. For instance, if user is looking at the right key, then the keyboard moves to the right direction with one key step and the characters of the five surrounding keys are changes simultaneously as shown in Figure 5.

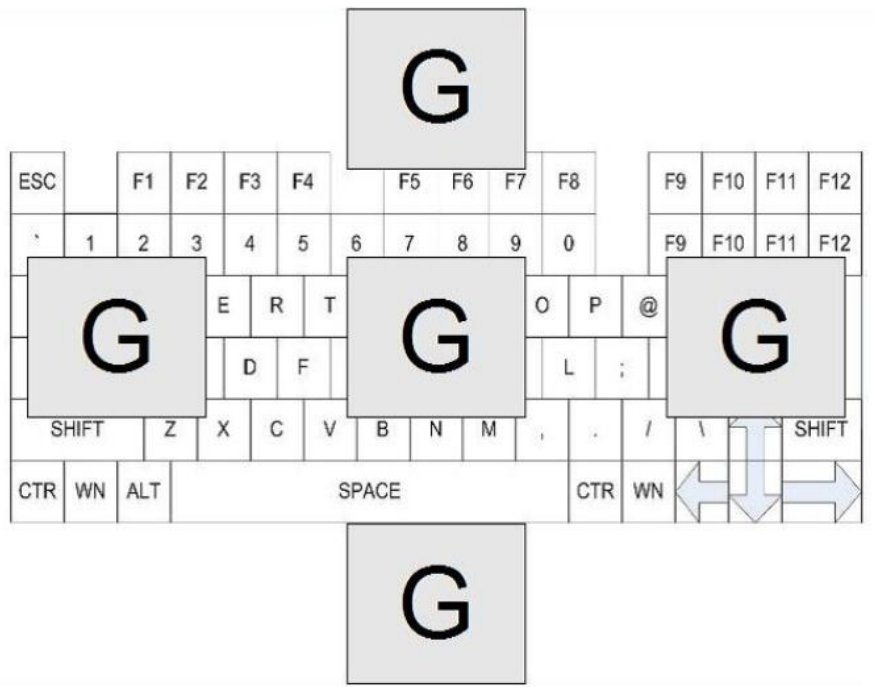

Fig.4. Key layout of the moving keyboard

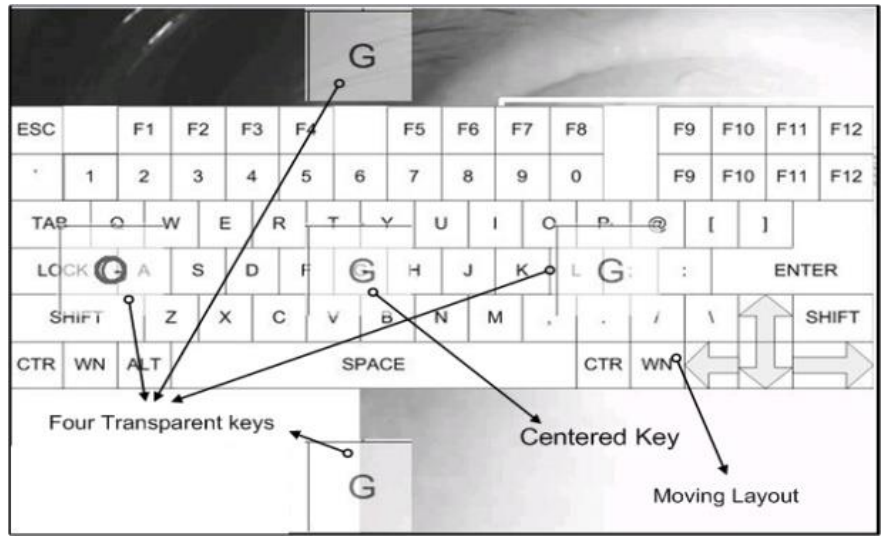

Fig.5. Key layout for the proposed moving keyboard (Circle denotes gaze location)

If the keyboard does not move, then the gaze location has to be determined precisely because key size is too small in comparison to the proposed moving keyboard. User has to retry key-in when the selected key is not intended key due to misidentification of key location results in it takes much longer time in comparison to the required key-in time for the proposed moving keyboard. Therefore, the proposed moving keyboard does not require precise gaze estimation accuracy and makes high success rate of key-in performance with relatively short time period.

\section{Camera Mouse}

All mouse event and key-in can be done with human eyes only [1]-[15]. In the camera mouse, comparatively high gaze estimation accuracy is needed for identifying icons which are displayed onto HMD screen. Icon hold is available to keep the previous click event by using one additional key for hold. Thus right or left button clicks and multiple key selections are available. For instance, $\mathrm{Ctl}+\mathrm{Alt}+\mathrm{Del}$ for task manager activation can be selected by using the hold key operation. Thus all the icons for application software including search 
engine can be activated. Therefore, user can use web services with the proposed wearable computing system.

\section{Indoor Location Estimation}

Some of the web services need the location information. When user is situated outdoor, GPS receiver included in smart phone, iPhone, or some other mobile devices is used. Location estimation accuracy of GPS receiver, however, is not good enough. It is not always that user is situated outdoor. Therefore, indoor location estimation is needed.

The authors proposed the indoor location estimation method and system. It achieved $2.5 \mathrm{~m}$ of location accuracy [16]. It would be enough for web services. The first step is to draw a two-dimensional map of the building for data collection and tracking.

Based on the map, we create the grid in a rectangle shape and data gathering route is determined. Each route is stored as one path, and the collected signal data can be stored for each Access Point (AP) on each grid.

The signal strength information collected in the operation outlined above, needs to be processed for noise reduction as well as for the purposes of building a signal strength distribution model. The signal strength data collected from the APs is processed using an adaptive Kalman filtering algorithm to eliminate the noise and interference effects. In building the signal distribution model, interpolation is applied. The signal distribution at each point on the data gathering route is stored in the Radiomap database of the server computer.

In the tracking phase, signal data are processed in real-time by the filtering algorithm of the RSSI is compared with that stored in Radiomap. Based on this comparison, the optimal location is determined and marked on the map efficiently using color representative visualization approach. Thus geolocation utilizing web services are available with the proposed wearable computing system.

\section{IMPLEMENTATION AND EXPERIMENTS}

\section{A. Hardware}

Table 1shows the major specifications for HMD while Table 2 shows the specification of the backward looking camera. These are attached to a glass. User wears the glass together with tablet PC and / or mobile device as wearable computing system.

TABLE I. SPECIFICATION OF SINGLE EYE OF HMD

\begin{tabular}{|c|c|}
\hline Resolution & SVGA $(800 \times 600$ pixels $)$ \\
Supposed distance & $2 \mathrm{~m}$ \\
Supposed size & 60 inch \\
Field of view & 42 degree \\
Input type & RGB \\
Operable temp。 & $0 \sim 40^{\circ} \mathrm{C}$ \\
Size & $28 \mathrm{~mm}(\mathrm{~W}) \times 35.24 \mathrm{~mm}(\mathrm{H}) \times 56 \mathrm{~mm}(\mathrm{D})$ \\
Weight & $20 \mathrm{~g}$ \\
& \\
\hline
\end{tabular}

TABLE II. SPECIFICATION OF NEAR INFRARED CAMERA

\begin{tabular}{|c|c|}
\hline Resolution & $1,300,000$ pixels \\
Minimum distance & $20 \mathrm{~cm}$ \\
Frame rate & $30 \mathrm{fps}$ \\
Minimum illumination & $301 \mathrm{ux}$ \\
Size & $52 \mathrm{~mm}(\mathrm{~W}) \times 70 \mathrm{~mm}(\mathrm{H}) \times 65 \mathrm{~mm}(\mathrm{D})$ \\
Weight & $105 \mathrm{~g}$ \\
\hline
\end{tabular}

\section{B. Software}

Figure 6 shows an example of the screen shot of displayed image onto the HMD display. Just behind the moving keyboard, there is an acquired face image. At the bottom right corner, there is an extracted eye image. White circle denotes the detected pupil. The extracted pupil image is situated just beside the bottom enlarged key "F" on the left. Also black circle which indicated the estimated gaze location is situated just bottom right corner of the left enlarged key " $F$ ". In this case, moving keyboard moves to the left key "D" just 0.5 second after user looks at the left enlarged key "F".

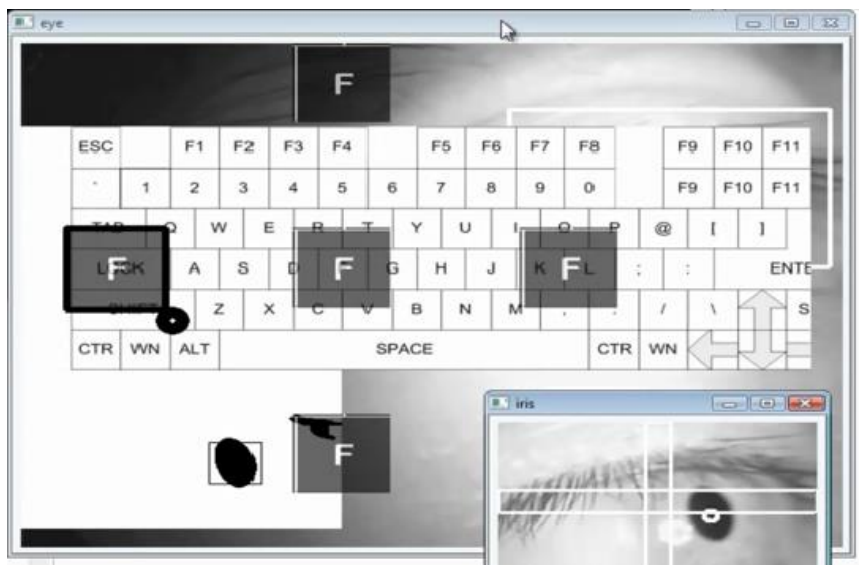

Fig.6. Example of the screen shot of displayed image onto the HMD display

\section{Time Required for Key-in}

If user looks at the center of enlarged key " $F$ " for more than 0.5 second, then the key " $F$ " is to be selected and determined. Therefore, it takes 0.5 to 5 seconds for one key-in results in approximately 2.5 seconds in average because key array consist five times ten keys typically. Figure 7 shows the time required for eye detection.

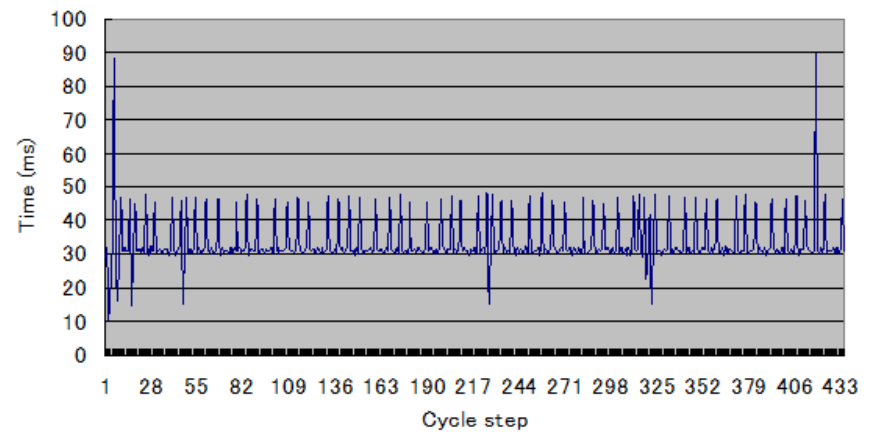

Fig.7. Processing time of eye detection and tracking on steady state condition, it looks faster than transient condition. 
Meanwhile, Figure 8 shows the time required for key-in.

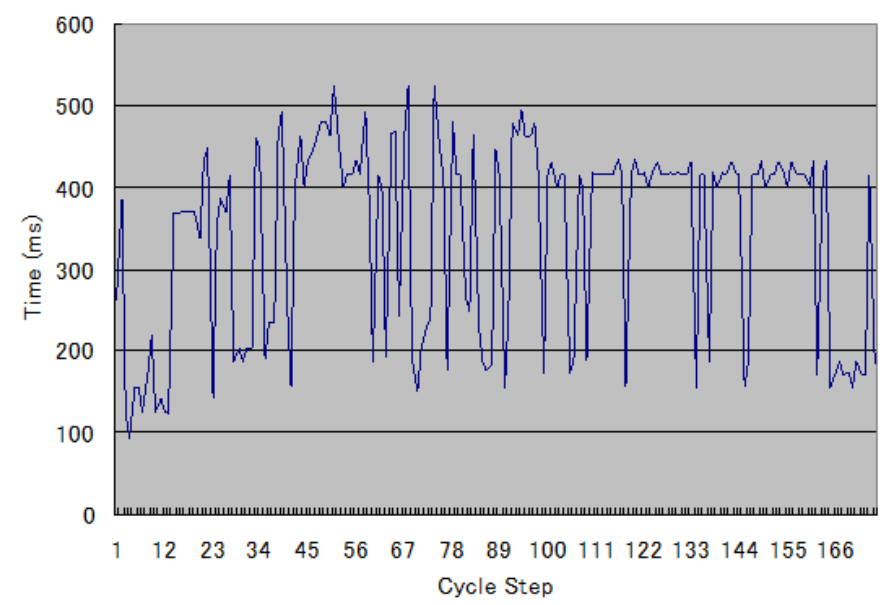

Fig.8. processing time of Eye gaze method

\section{Mouse Operation}

Mouse events are available for the proposed wearable computer. Therefore, application software can be activated ny eye based mouse. At the bottom of Figure 9, there is the window for the word processing software is situated. User may confirm the character of which user selected and determined in the opened window.

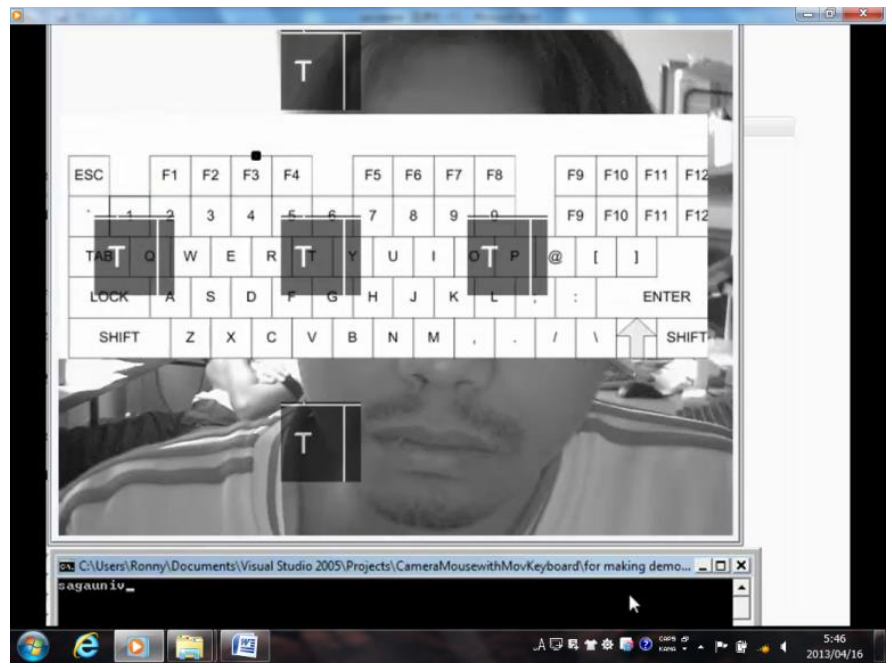

Fig.9. Another window can be opened by using the eye based mouse

\section{E. Key-in Success Rate}

Key-in success rate depends on the gaze location. Success rate for four corners are much worth than those for center and top, bottom right and left. Due to the fact that enlarged five keys are situated at center and top, bottom right and left of the screen display. Therefore, key-in success rate is almost $100 \%$ for the key location of plus minus 15 degree in pitch direction and for the key locations of plus minus 30 degree in roll direction. The success rate in the horizontal direction is better than those in vertical direction. Meanwhile, success rate for the case that pitch angle is more than 20 degree gets worth as shown in Table 3.
TABLE III. KEY-IN SUCCESS RATE

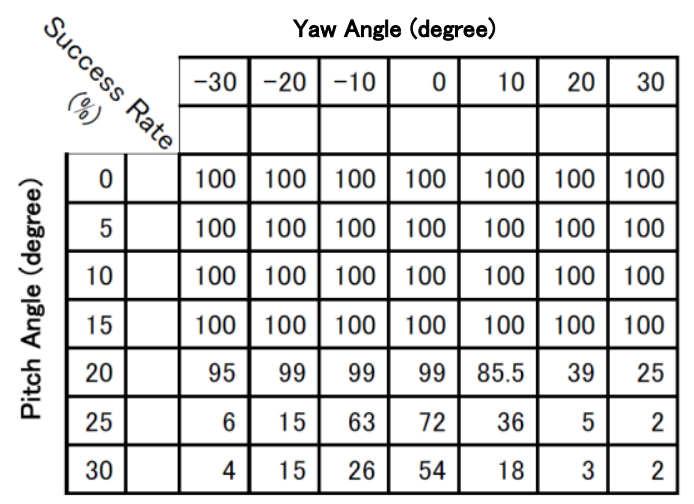

\section{F. One of Applications of the Proposed Wearable Computing} System

One of the applications of the proposed wearable computer is Google search. By using the proposed eye based mouse, Google search engine can be activated. Then keywords also be typed in the dialog box as keywords for Google search as shown in Figure 10..

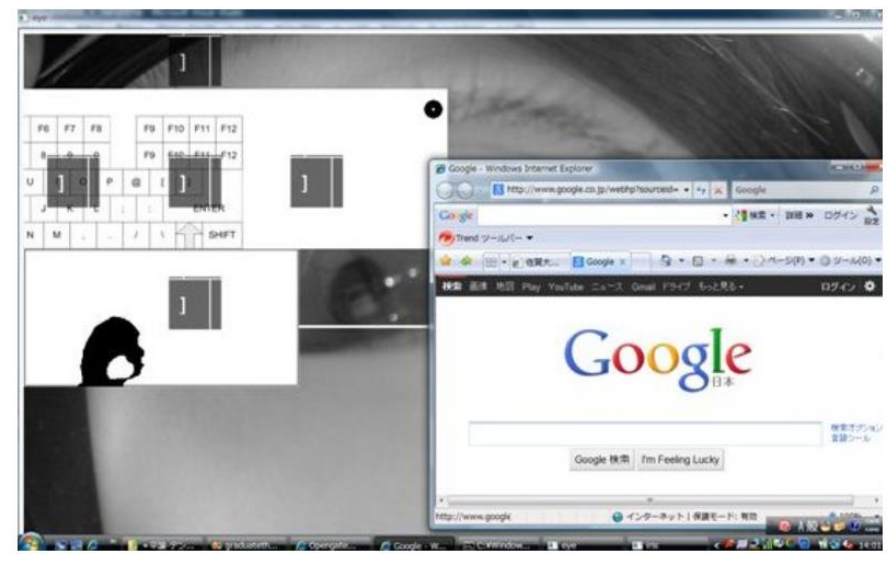

Fig.10. Google search as an example of applications of the proposed wearable computing system

\section{G. Location Based Web Services}

Another example of applications of the proposed system is location based web services. Even if user is situated in house at where GPS signal cannot be reached, indoor location estimation can be done by using the signals from the near WiFi access points. The experiments are conducted for the building situation as shown in Figure 11.There are three access points in the building. User has mobile devices with $\mathrm{WiFi}$ receivers and walks in the buildings. Six locations are tested for evaluation of location estimation accuracy. User may recognize the $\mathrm{WiFi}$ access point ID. Therefore, discrimination of the signals from each access point can be easily done. Figure 12 shows an example of the received signal from each access point. By using signal strength differences from the different three WiFi access points, user may estimate own location as shown in Figure 13. Evaluation results of location estimation accuracy are shown in Table 4. 


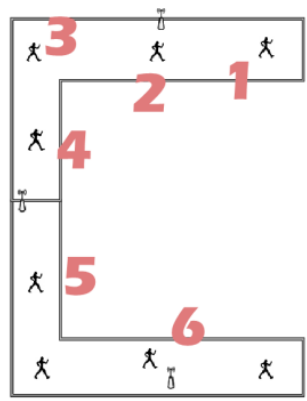

Fig.11. Experimental situation of user location and WiFi access point locations (Position \#1: 3 meters, \#2: 15 meters, \#3:46 meters, \#4:72 meters, \#5:92 meters, and \#6:132 meters)

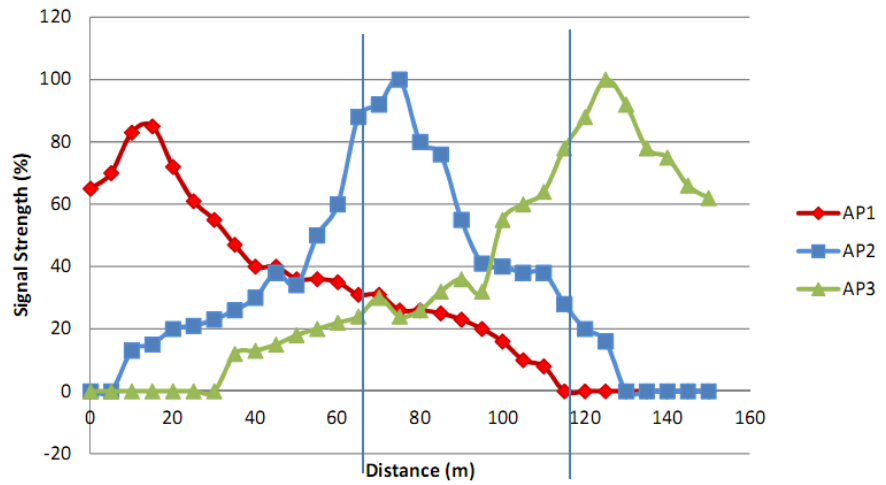

Fig.12. Received signals from each WiFi access point

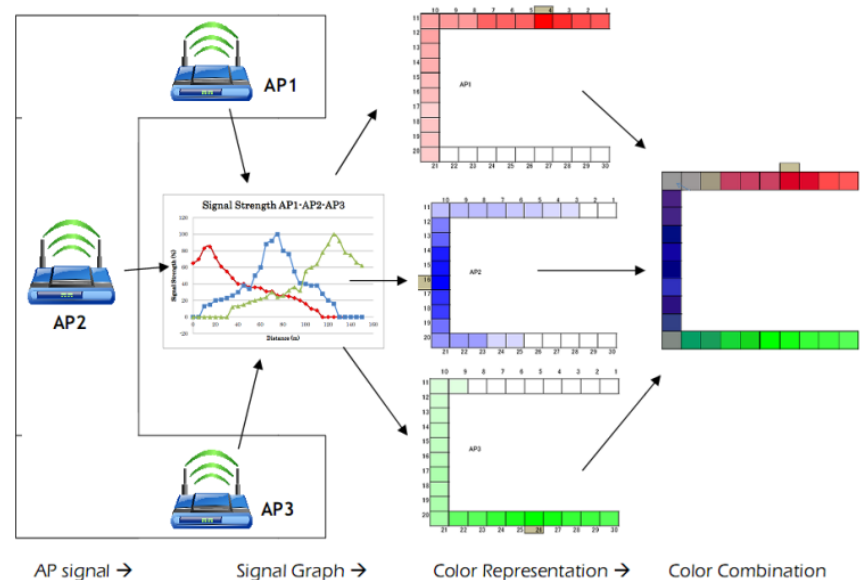

Fig.13. Three color coded received signals make estimation of user(s location

TABLE IV. GRID ESTIMATION RESULTS FOR 6 SAMPLES WITH ERROR

\begin{tabular}{|c|c|c|c|c|}
\hline No & $\begin{array}{c}\text { Online Position } \\
\text { (meters) }\end{array}$ & Estimated Grid & $\begin{array}{c}\text { Min } \\
\text { Error } \\
\text { (meters) }\end{array}$ & $\begin{array}{c}\text { Max } \\
\text { Error } \\
\text { (meters) }\end{array}$ \\
\hline 1. & 3 & Grid $1[0 \mathrm{~m}-5 \mathrm{~m}]$ & 2 & 3 \\
\hline 2. & 15 & Grid 2 [15m-20m] & 0 & 5 \\
\hline 3. & 46 & Grid $10[45 \mathrm{~m}-50 \mathrm{~m}]$ & 1 & 4 \\
\hline 4. & 72 & Grid $15[70 \mathrm{~m}-75 \mathrm{~m}]$ & 2 & 3 \\
\hline 5. & 92 & Grid $19[90 \mathrm{~m}-95 \mathrm{~m}]$ & 2 & 3 \\
\hline 6 & 132 & Grid 27 [130m-135m] & 3 & 3 \\
\hline
\end{tabular}

\section{CONCLUSION}

Wearable computing with Input-Output devices Base on Eye-Based Human Computer Interaction: EBHCI which allows web services, location/attitude/health condition monitoring is proposed. Through implementation of the proposed wearable computing system, all the functionality is confirmed. It is also found that the system does work well. It can be used easily and also is not expensive. Experimental results for EBHCI show excellent performance in terms of key-in accuracy as well as input speed. It is accessible to internet, obviously, and has search engine capability.

It is also found that location based web services are available with the proposed wearable computing system because the location estimation accuracy of $2.5 \mathrm{~m}$ is a good enough for the services.

\section{ACKNOWLEDGMENT}

The author would like to thank Dr. Ronny Mardiyanto of the Institute Technology Surabaya and Dr. Herman Tolle of Brawijaya University for their great effort to conduct experiments of eye based human computer interaction and indoor location estimation. The author also would like to thank Mr. Fujise for his effort to conduct experiment of wearable computing system.

\section{REFERENCES}

[1] Hailing Zhou, Lijun Xie, Xuliang Fang, "Visual Mouse: SIFT Detection and PCA Recognition," Proceedings of the International Conference on Computational Intelligence and Security Workshops (CISW 2007), 263266, 2007

[2] M.E. Erdem, I.A. Erdem, V. Atalay, A.E. Cetin, "Computer vision based unistroke keyboard system and mouse for the handicapped," Proceedings of the International Conference on Multimedia and Expo - Volume 2 (ICME '03), 765-768, 2003

[3] Luca Lombardi, Marco Porta, "Adding Gestures to Ordinary Mouse Use: a New Input Modality for Improved Human-Computer Interaction," Proceedings of the 14th International Conference on Image Analysis and Processing (ICIAP 2007), 461-466, 2007

[4] Jilin Tu, Thomas Huang, Hai Tao, "Face as Mouse Through Visual Face Tracking," Proceedings of the 2nd Canadian Conference on Computer and Robot Vision (CRV'05), 339-346, 2005

[5] Nikolay Stefanov, Aphrodite Galata, Roger Hubbold, "Real-time Hand Tracking With Variable-Length Markov Models of Behavior," Proceedings of the IEEE Computer Society Conference on Computer Vision and Pattern Recognition (CVPRW'05) - Workshops, 73, 2005

[6] Yun Fu, Thomas S. Huang, "hMouse: Head Tracking Driven Virtual Computer Mouse," Proceedings of the 8th IEEE Workshop on Applications of Computer Vision (WACV'07), 30, 2007

[7] Takeshi Kurata, Takashi Okuma, Masakatsu Kourogi, Katsuhiko Sakaue, "The Hand Mouse: GMM Hand-Color Classification and Mean Shift Tracking," Proceedings of the IEEE ICCV Workshop on Recognition, Analysis, and Tracking of Faces and Gestures in Real-Time Systems (RATFG-RTS'01), 119, 2001

[8] T. Ohno, "Features of Eye Gaze Interface for Selection Tasks," Proceedings of the 3rd Asian Pacific Computer and Human Interaction, 176, 1998

[9] Zhu Hao, Qianwei Lei, "Vision-Based Interface: Using Face and Eye Blinking Tracking with Camera," Proceedings of the 2nd International Symposium on Intelligent Information Technology Application, 1, 306310, 2008J. Clerk Maxwell, A Treatise on Electricity and Magnetism, 3rd ed., vol. 2. Oxford: Clarendon, 1892, pp.68-73.

[10] Arai K. and H. Uwataki, Computer key-in based on gaze estimation with cornea center determination which allows students' movement, Journal of Electrical Engineering Society of Japan (C), 127、7、1107-1114、 2007 
[11] Arai K. and H. Uwataki, Computer input system based on viewing vector estimation with iris center detection from face image acquired with web camera allowing students' movement, Electronics and Communication in Japan, 92, 5, 31-40, John Wiley and Sons Inc.,2009.

[12] Arai K., and M. Yamaura, Blink detection accuracy improvements for computer key-in by human eyes only based on molforgic filter, Journal of Image Electronics Engineering Society of Japan, 37、5、601-609、 2008.

[13] Arai K. and R. Mardiyanto, Real time blinking detection based on Gabor filter, International Journal of Human Computer Interaction, 1, 3, 33-45, 2010.

[14] Arai K. and R. Mardiyanto, Camera mouse and keyboard for handicap person with trouble shooting capability, recovery and complete mouse events, International Journal of Human Computer Interaction, 1, 3, 46$56,2010$.

[15] Arai K. and M. Yamaura, Computer input with human eyes only use two Purkinje images which work in a real time basis without calibration, International Journal of Human Computer Interaction, 1, 3, 71-82, 2010.

[16] Arai K., and K. Yajima, Communication aid based on computer key-in with human eyes only, Journal of Electric Engineering Society of Japan, (C), 128 -C, 11, 1679-1686, 2008.

[17] Djoko P., R. Mardiyanto and K. Arai, Electric wheel chair control with gaze detection and eye blinking, Artificial Life and Robotics, AROB Journal, 14, 694,397-400, 2009.

[18] Arai K. and K. Yajima, Communication Aid and Computer Input System with Human Eyes Only, Electronics and Communications in Japan, 93, 12, 1-9, John Wiley and Sons, Inc., 2010.

[19] Arai K., R. Mardiyanto, A prototype of electric wheel chair control by eye only for paralyzed student, Journal of Robotics and Mechatronics, 23, 1, 66-75, 2010.

[20] Arai K. and K. Yajima, Robot arm utilized having meal support system based on computer input by human eyes only, International Journal of Human Computer Interaction, 2, 1, 120-128, 2011.

[21] Arai K. and T. Herman, Automatic e-comic content adaptation, International Journal of Ubiquitous Computing, 1,1,1-11,2010
[22] Arai K., T. Herman, "Method for Real Time Text Extraction from Digital Manga Comic", International Journal of Image Processing, 4, 6, 669-676, 2011.

[23] Arai K., T. Herman, Module based content adaptation of composite elearning content for delivering to mobile devices, International Journal of Computer Theory and Engineering, 3, 3, 381-386, 2011.

[24] Arai K., T. Herman, Method for extracting product information from TV commercial, International Journal of Advanced Computer Science and Applications, 2, 8, 125-131, 2011

[25] Arai K., T. Herman "Module Based Content Adaptation of Composite ELearning Content for Delivering to Mobile Learners", International Journal of Computer Theory and Engineering (IJCTE), Vol 3, No. 3, pp. 381-386, June 2011

[26] Arai K., T. Herman, Efficiency improvements of e-learning document search engine for mobile browser, International Journal of Research and Reviews on Computer Science, 2, 6, 1287-1291, 2011.

[27] Arai K., R. Mardiyanto, Evaluation of Students' Impact for Using the Proposed Eye Based HCI with Moving and Fixed Keyboard by Using EEG Signals, International Journal of Review and Research on Computer Science(IJRRCS), 2, 6, 1228-1234, 2011

\section{AUTHORS PROFILE}

Kohei Arai, He received BS, MS and PhD degrees in 1972, 1974 and 1982 respectively. He was with The Institute for Industrial Science and Technology of the University of Tokyo from April 1974 to December 1978 and also was with National Space Development Agency of Japan from January, 1979 to March, 1990. During from 1985 to 1987, he was with Canada Centre for Remote Sensing as a Post Doctoral Fellow of National Science and Engineering Research Council of Canada. He moved to Saga University as a Professor in Department of Information Science on April 1990. He was a councilor for the Aeronautics and Space related to the Technology Committee of the Ministry of Science and Technology during from 1998 to 2000. He was a councilor of Saga University for 2002 and 2003. He also was an executive councilor for the Remote Sensing Society of Japan for 2003 to 2005 . He is an Adjunct Professor of University of Arizona, USA since 1998. He also is Vice Chairman of the Commission A of ICSU/COSPAR since 2008. He wrote 26 books and published 327 journal papers. 